\title{
Correction to: Policy-specific alienation and indifference in the calculus of voting: a simultaneous model of party choice and abstention
}

\section{Paul W. Thurner ${ }^{1} \cdot$ Angelika Eymann $^{1}$}

Published online: 26 June 2018

(c) Springer Science+Business Media, LLC, part of Springer Nature 2018

\section{Correction to: Public Choice 102: 51-77, 2000} https://doi.org/10.1023/A:1005046024214

Figure 2 on page 57 was erroneously duplicated in Fig. 3 in the typesetting process. Actually, Fig. 3 should have been rendered as follows:

Fig. 3 Party choice and abstention choice/decision tree III

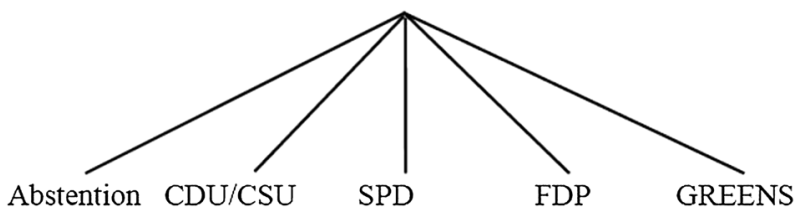

The original article can be found online at https://doi.org/10.1023/A:1005046024214.

Paul W. Thurner

paul.thurner@gsi.uni-muenchen.de

1 Universität Mannheim, Seminargebäude A5, 68131 Mannheim, Germany 